\title{
Elevated high sensitivity C-reactive protein and uric acid levels in coronary artery ectasia
}

\author{
Şerafettin Demir ${ }^{1 凶}$, Gulhan Karakoyun ${ }^{2}$ and Mehmet Kanadasi ${ }^{3}$ \\ 'Department of Cardiology, Adana State Hospital, Adana, Turkey; ${ }^{2}$ Çukurova University, School of Medicine, Department of Biochemistry, Adana, \\ Turkey; ${ }^{3}$ Çukurova University, School of Medicine, Department of Cardiology, Adana, Turkey
}

\begin{abstract}
Aim: The aim of this study is to examine uric asid (UA) and high sensitive C-Reactive protein (Hs-CRP) levels in patients with coronary artery ectasia (CAE). Materials and Methods: Ninety-eight patients with isolated CAE (mean age $57.5 \pm 10.3$ ), (group-I), 110 patients with CAD but without CAE (mean age 56.3 \pm 10.7 ), (group-II), and 105 patients with normal coronary angiographies (mean age 58.1 \pm 10.8 ), (group-III) were included in the study. Blood samples of all individual were taken after coronary angiography from an antecubital vein, the patients uric acid and Hs-CRP levels were assessed. The severity of ectasia was evaluated and categorized according to Markis. Results: A significant difference was not seen in serum uric acid and Hs-CRP levels between CAE and CAD groups. However, relative to the control group, uric acid and Hs-CRP levels in CAE and CAD groups were higher to a significant degree $(p=0.001, p<0.001$, respectively), $(p<0.001, p<0.001$, respectively). The statistical significant was detected between subgroups type I and type IV, Hs-CRP and UA were statistically high in subgroup type I. ( $p=0.012, p=0.033$, respectively) In multiple regression analysis, $C A E$ and $C A D$ were independently associated with UA $(\beta=0.76 ; p<0.001, \beta=0.68 ; p<0.001$, respectively) and Hs-CRP ( $\beta=0.66 ; p<0.01, \beta=0.62 ; p<0.01$, respectively) along with diabetes mellitus $(\beta=0.61$; $p=0.039, \beta=0.94 ; p=0.028$, respectively). Conclusion: In conclusion, the blood uric acid and Hs-CRP values in our study have been observed to be higher in the individuals with coronary arteri ectasia in comparison to normal individuals, and the increase in these values were found to be parallel to the extent of the ectasia.
\end{abstract}

Key words: coronary ectasia, coronary artery disease, uric acid, high sensitive C-reactive protein

Received: 20 May, 2013; revised: 23 January, 2014; accepted: 04 March, 2014; available on-line: 07 October, 2014

\section{INTRODUCTION}

Coronary artery ectasia (CAE) is defined as diffuse or local dilatation of the epicardial coronary arteries without obstruction (Hartnell et al., 1995). According to Falsetti and Befeler, a 1.5 to 2 fold dilatation of a normal coronary artery angiogram constitute CAE. A larger than two-fold increase is considered a coronary aneurysm. Underlying etiological causes include atherosclerosis $(50 \%)$, congenital origins (20-30\%), and inflammatory and connective tissue diseases (20-30\%) (Falsetti et al., 1976; Befeler et al., 1977). Coronary artery disease (CAD) and the occurrence of atheromatous ulcerations in the ectatic segment are frequently concomitant with CAE. The major cause of CAE is thought to be atherosclerosis (Swaye et al., 1983; Seabra Gomes, 1974). Inflammation is known to play a role in all stages of atherosclerosis. Studies have confirmed that the inflammatory protein high sensitive C-Reactive Protein (Hs-CRP) is an important indicator of atherosclerosis (Stefanadis et al., 2000; Koşar et al., 2005). In previous studies it was found that increased serum uric acid (UA) level is an independent and statistically significant predictor of ischemic heart disease and cardiovascular mortality (NHANES I) (Torzewski et al., 1998). In individuals with obesity, glucose intolerance (Koga et al., 2009), renal disease, (Fang et al., 2000), hyperlipidemia, atherosclerosis (Puig et al., 1991), and hypertension (Puig \& Ruilope, 1999), it was shown that an increase of the serum uric acid level played a part in the pathogenesis of CAD.

In the previous studies it was shown that there is a relation between Hs-CRP and UA in coronary artery disease. However, to present, there has not been a study that showed a clear relationship between uric acid and Hs-CRP levels in individuals with CAE. This study aimed to show the correlation between uric acid and HsCRP levels in CAE patients.

\section{MATERIAL AND METHOD}

We studied prospectively patients between 2008 and 2012 from individuals referred for coronary angiography due to the presence of typical angina and/or abnormal noninvasive test results suggesting myocardial ischemia. Three groups were studied. Group I: these were 98 patients with isolated CAE showing ectatic coronaries without any visible stenosis; group II: age and sex matched 110 patients with CAD; and group III: age and sex matched 105 normal healthy controls with a normal coronary angiography. Patients medical histories, electrocardiogram, complete blood count, urea, creatinine, serum sodium, potassium, total cholesterol, triglyceride, high density lipoprotein (HDL) and low density lipoprotein (LDL) levels were assessed. The included patients were evaluated in terms of age, sex, and risk factors. Hypertension was defined as systolic blood pressure of $140 \mathrm{mmHg}$ or above, diastolic blood pressure of $90 \mathrm{mmHg}$ or above, or use of antihypertensive medication. Diabetes mellitus was defined fasting blood glucose

\footnotetext{
e-mail: demirkardiyoloji@hotmail.com
}

Abbreviations: UA, Uric Acid; Hs-CRP, High sensitive C-Reactive protein; CAE, Coronary artery ectasia; CAD, Coronary artery disease; HDL, High density lipoprotein; LDL, Low density lipoprotein 
Table 1. Demographic characteristics of patients

\begin{tabular}{|c|c|c|c|c|c|c|}
\hline & Group 1 & Group 2 & Group 3 & \multirow{2}{*}{$P_{1}$} & \multirow{2}{*}{$P_{2}$} & \multirow{2}{*}{$\mathrm{P}_{3}$} \\
\hline & Mean \pm S.D. & Mean \pm S.D. & Mean \pm S.D. & & & \\
\hline Age (years) & $57.5 \pm 10.3$ & $56.3 \pm 10.7$ & $58.1 \pm 10.8$ & 0.409 & 0.369 & 0.247 \\
\hline Sex (Male) & $66(68.4 \%)$ & $75(69.7 \%)$ & $73(69.5 \%)$ & 0.362 & 0.488 & 0.532 \\
\hline Smoking & $64(65.3 \%)$ & $69(62.7 \%)$ & $63(60.0 \%)$ & 0.339 & 0.104 & 0.251 \\
\hline Heart Rate (bpm) & $83.7 \pm 14.6$ & $84.4 \pm 16.6$ & $86.4 \pm 16.3$ & 0.363 & 0.176 & 0.485 \\
\hline Hematocrit (gr/dl) & $34.8 \pm 4.9$ & $35.9 \pm 4.3$ & $35.3 \pm 4.1$ & 0.281 & 0.311 & 0.437 \\
\hline LDL (mgr/dl) & $152.6 \pm 48.6$ & $148.7 \pm 46.1$ & $156.2 \pm 48.5$ & 0.144 & 0.349 & 0.097 \\
\hline Urea (mgr/dl) & $31.4 \pm 6.9$ & $32.1 \pm 6.6$ & $31.5 \pm 7.6$ & 0.164 & 0.152 & 0.214 \\
\hline DM (n, \%) & $22(22.4 \%)$ & $25(22.7 \%)$ & $23(21.9 \%)$ & 0.138 & 0.342 & 0.218 \\
\hline HT (n, \%) & $42(42.8 \%)$ & $46(41.8 \%)$ & 44 (41.9\%) & 0.147 & 0.283 & 0.201 \\
\hline
\end{tabular}

LDL, Low density lipoprotein; DM, Diabetes mellitus; HT, Hypertension; P1, Group I versus Group II; P2, Group I versus Group III; P3, Group II versus Group III

of $126 \mathrm{mg} / \mathrm{dl}$ or above, current antidiabetic treatment, or application of a diet. Patients who were smoking 1 or more cigarettes per day at the time of diagnosis were defined as smokers.

Patients with any of the following were excluded. Acute coronary syndrome, a history of previous coronary artery disease, a history of beta blockers, statin, antiplatelet or anticoagulant use, valvular heart disease, heart failure, renal and hepatic dysfunction, hematological disorders, history of malignancy and other chronic systemic disorders, inflammatory and connective tissue diseases, acute or chronic infection and stroke. All patients and control individuals who were participated to the study gave informed consent and the study was approved by the local ethics committee.

Coronary angiography. Coronary angiography was performed by the Judkins or Sones technique without the use of nitroglycerin using 6-French right and left heart catheters. Angiograms were analyzed by two blinded interventional cardiologists without knowledge of the clinical status or laboratory measurements. Coronary diameter was measured as the maximum diameter of the ectasic segment using a computerized quantitative coronary angiographic analysis system. Isolated CAE was defined as a coronary artery segment with a diameter of 1.5-2 times the adjacent coronary segment. If no normal adjacent segment existed, the mean diameter of the same coronary artery in the control group served as the normal value. The coronary artery disease patients were selected in a consecutive manner from the catheterized patients during the same study period and who had 50\% or more stenosis at coronary angiograms. The control group were selected in a consecutive manner from the catheterized patients during the same study period and who proved to have normal coronary angiograms. The severity of ectasia was evaluated and categorized accord- ing to Markis. (Markis et al., 1976) In decreasing order of severity, diffuse ectasia of two or three vessels was classified as Type I, diffuse disease in one vessel and localized disease in another vessel as Type II, diffuse ectasia of one vessel only as Type III and localized or segmental ectasia as Type IV.

Biochemical measurements. Collection of specimens. Blood samples of all individual were taken after coronary angiography from an antecubital vein. Serum samples was taken from vein by $10 \mathrm{cc}$ syringe into the 2 Vacuette Blood Collection Tube with Serum Clot Activator, Gel Seperator for biochemical analyses. The tubes delivered to the laboratory as soon as and centrifuged with $300 \mathrm{~g}$ around 10 minutes.

Immunoassays. Serum UA levels analyzed by immunoturbidimetric method with Beckman Coulter kit in Beckman UnicelDxC 800 Synchron (Beckman Coulter Inc., CA, USA) auto-analyzer. Analytical range of serum uric acid was $0.5-12.0 \mathrm{mg} / \mathrm{dL}(30-714 \mu \mathrm{mol} / \mathrm{L})$. Sensitivity for URIC determination was $0.5 \mathrm{mg} / \mathrm{dL}$ (30 $\mu \mathrm{mol} / \mathrm{L})$ for serum.

Serum Hs-CRP analyzed by immunonephelometric method with Beckman Coulter kit in Beckman Immage 800 (Beckman Coulter Inc., CA, USA) nephelometer. Analytical range of serum was HS-CRP $0.02-8.0 \mathrm{mg} / \mathrm{dL}$ $(0.2-80.0 \mathrm{mg} / \mathrm{L})$ and analytical sensitivity for HS-CRP determination was $0.02 \mathrm{mg} / \mathrm{dL}(0.2 \mathrm{mg} / \mathrm{L})$.

Statistical analysis. Statistical analysis was performed using the statistical package SPSS v 17.0. For each continuous variable, normality was checked by Kolmogorov Smirnov and Shapiro-Wilk tests and by histograms.. The catagorical variables between the groups was analyzed by using the Chi square test OR Fisher Exc. Test. All numerical data are expressed as median values (min-max) or as proportions. Comparisons between groups were applied using one way ANOVA test for normally dis-

Table 2. Comparative analysis plasma level of Hs-CRP, and uric asid among different study groups.

\begin{tabular}{llllll}
\hline & Goup I & Group II & Group III & P1 & P2 \\
\hline Hs-CRP $(\mathrm{mg} / \mathrm{dL})$ & $3.1 \pm 1.0$ & $3.2 \pm 0.8$ & $1.8 \pm 0.9$ & 0.248 & $>0.01$ \\
\hdashline Uric Asid $(\mathrm{mg} / \mathrm{dL})$ & $6.4 \pm 1.4$ & $6.3 \pm 1.3$ & $5.8 \pm 1.4$ & 0.341 & $>0.01$ \\
\hline
\end{tabular}

Hs-CRP, High sensitive C-Reactive protein; P1, Group I versus Group II; P2, Group I versus Group III; P3, Group II versus Group III 
Table 3. Eveluation Hs-CRP and Uric Asid Levels According Type of Coronary Ectasia Severity

\begin{tabular}{llcl}
\hline Type & $\mathrm{n}(\%)$ & $\begin{array}{c}\text { Hs-CRP } \\
(\mathrm{mg} / \mathrm{dL})\end{array}$ & $\begin{array}{l}\text { Uric Asid } \\
(\mathrm{mg} / \mathrm{dL})\end{array}$ \\
\hline Type I & $26(20.6)$ & $3.6 \pm 0.5$ & $8.1 \pm 2,2$ \\
\hline Type II & $30(23.8)$ & $3.0 \pm 0.7$ & $6.3 \pm 1.8$ \\
\hline Type III & $38(30.2)$ & $3.1 \pm 0.4$ & $6.1 \pm 2.4$ \\
\hline Type IV & $32(25.4)$ & $2.7 \pm 0.6$ & $5.5 \pm 3.1$ \\
\hline
\end{tabular}

Type 1 - diffuse ectasia of two or three vessels; Type 2 - diffuse ectasia in one vessel and localized ectasia in another vessel; Type 3 - diffuse ectasia of one vessel only; Type 4 - localized or segmental ectasia (group 4).

trubited data and Kruskal Wallis test were used for the data not normally distrubited. Since analysis of variance was significant, comparisons were applied using the Post Hoc test and Mann-Whitney $U$ test. A logistic regression analysis was used to know associations between coronary artery ectasia and other laboratory measurements, with coronary artery ectasia as dependent variable. Values of $\mathrm{p}<0.05$ were considered statistically.

Correlations between parameters were tested by Spearman's correlation test. Spearman's correlation coefficients were interpreted as either excellent relationship $r \geq 0.91$; good $0.90 \leq \mathrm{r} \geq 0.71$; fair $0.70 \leq \mathrm{r} \geq 0.51$; weak $0.50 \leq \mathrm{r} \geq 0.31$; little or none $r \leq 0.3$ (ref). A $p$ value of 0.01 was taken as the level of significance.

\section{RESULTS}

Baseline demographic and clinical characteristics data are summarized in Table 1. There were no statistical differences as regards age, sex, smoking, heart rate, hematocrit, LDL, urea, diabetes mellitus, and hypertension among the three groups.

The plasma level groups and the Hs-CRP and uric acid values are presented in Table 2. When Group I and Group II are compared, no statistically significant difference was observed in terms of Hs-CRP and uric acid levels $(p=0.248$ and $p=0.341$, respectively). When Group I and Group II were compared with Group III, Hs-CRP and uric acid levels were observed to be statistically significantly higher in both groups in relation to Group III $(p<0.01$ and $p<0.01$, respectively).

Ectasias severity were categorized in accordance with Markis categorization. (Table 3) MPV were compared among subgroups. The statistical significant was detected between type I and type IV subgroups, Hs-CRP and UA were statistically high in subgroup type I subgroup. $(p=0.012, p=0.033$, respectively) There were no statistically significant differences in Hs-CRP and UA among other subgroups defined according to CAE severity.

The correlations between coronary arterial ectasia and the demographic and clinical variables are evaluated in Table 4. The results have pointed out positive correlations between coronary arterial ectasia and cigarette smoking, DM, Hs-CRP and uric acid levels $(\mathrm{r}=0.27$, $r=0.32, r=0.42$ and $r=0.38$, respectively).

Based on the results of the correlation analysis and the univariate analysis, the risk factors influencing the coronary artery ectasia have been evaluated. Variables such as age, gender, DM, Ht, cigarette smoking, serum uric acid levels and Hs-CRP were included in the regression model. Diabetes mellitus, serum uric acid levels in quartile 4 , and Hs-CRP in quartile 2 and 3 were found to be the risk factors influencing the presence of cor-
Table 4. Univariate analysis of variables associated with coronary artery ectasia.

\begin{tabular}{lll}
\hline Variables & $\mathrm{r}$ & $\mathrm{p}$ \\
\hline Age & 0.05 & $\mathrm{NS}$ \\
\hline Sex & 0.08 & $\mathrm{NS}$ \\
\hline Smoking & 0.27 & 0.049 \\
\hline Heart Rate $(\mathrm{bpm})$ & 0.10 & $\mathrm{NS}$ \\
\hline Hematocrit(gr/dl) & 0.12 & $\mathrm{NS}$ \\
\hline LDL $(\mathrm{mgr} / \mathrm{dl})$ & 0.09 & $\mathrm{NS}$ \\
\hline Urea $(\mathrm{mgr} / \mathrm{dl})$ & 0.05 & $\mathrm{NS}$ \\
\hline DM $(\mathrm{n}, \%)$ & 0.32 & 0.027 \\
\hline HT $(\mathrm{n}, \%)$ & 0.17 & $\mathrm{NS}$ \\
\hline Hs-CRP $(\mathrm{mg} / \mathrm{dL})$ & 0.42 & 0.002 \\
\hline Uric Asid $(\mathrm{mg} / \mathrm{dL})$ & 0.38 & 0.01 \\
\hline
\end{tabular}

LDL — Low density lipoprotein, DM — Diabetes mellitus; HT — Hypertension; Hs-CRP - High sensitive C-Reactive protein

onary artery ectasia. In patients with diabetes, the rate of coronary artery ectasia was 1.8-times higher (95\% $\mathrm{CI}=1.3-3.3)$. Uric acid levels in quartile 4 (6.4-9.2 mg/ dL) increased the incidence of coronary artery ectasia by 2.4 (95\% CI of 1.1-5.2). Also, Hs-CRP levels in quartile 2 increased the incidence of coronary artery ectasia by $1.9(95 \% \mathrm{CI}=1.0-5.8)$, while levels in quartile 3 increased this incidence by 2.4 (\%95 CI=1.4-3.2) (Table 4).

In multiple regression analysis, $\mathrm{CAE}$ and $\mathrm{CAD}$ was independently associated with UA $(\beta=0.76 ; p<0.001$, $\beta=0.68 ; p<0.001$, respectively) and Hs-CRP $(\beta=0.66$; $p<0.01, \beta=0.62 ; p<0.01$, respectively) along with diabetes mellitus $(\beta=0.61 ; p=0.039, \beta=0.94 ; p=0.028$, respectively).

\section{DISCUSSION}

The main finding of our study is the identification of the significant highness of Hs-CRP and UA levels in individuals having isolated CAE and the significant correlation between these two parameters. The common concomitance with CAD has led to the suggestion that CAE is a type of CAD. Coronary atherosclerosis is present in 50 percent or greater of patients with coronary CAE; however, it may be seen occasionally with connective tissue disease and vasculitis also (Falsetti et al., 1976; Befeler et al., 1977). The exact mechanism responsible for CAE formation is unidentified. Furthermore, the underlying mechanism of isolated CAE without associated CAD has not been defined clearly yet. It has been suggested that coronary ectasia indicates a form of arterial remodeling in response to local plaque growth. Arterial remodeling comprises changes in the total arterial cross sectional area; the area within the external elastic membrane exposed to local hemodynamic and biochemical factors (Glagov et al., 1987).

There is increasing evidence pointing to the role of inflammation in every phase of atherosclerosis. The inflammatory protein Hs-CRP directly contributes to the atherosclerotic process. Conversely, increased atherosclerotic burden increases the Hs-CRP levels. High sensitivity-CRP is stored within the intima of the early atherosclerotic lesions and it is chemotactic for the monocytes (Torzewski et al., 2000). The advent of the Hs-CRP test has greatly contributed to our understanding the 
Table 4. Odds ratio of coronary artery ectasia according to demographic variables

\begin{tabular}{|c|c|c|}
\hline Variable & $\begin{array}{l}\text { Crude OR } \\
(95 \% \mathrm{Cl})\end{array}$ & $\begin{array}{l}\text { Adjusted OR } \\
(95 \% \mathrm{Cl})\end{array}$ \\
\hline \multicolumn{3}{|l|}{ Age } \\
\hline$\leq 59$ years/ $>60$ years & $1.37(0.65-4.01)$ & $1.46(0.77 .-4.28)$ \\
\hline \multicolumn{3}{|l|}{ Gender } \\
\hline Famale/Male & $1.43(0.73-3.32)$ & $1.52(0.83-2.95)$ \\
\hline \multicolumn{3}{|l|}{ Diabetes } \\
\hline No/Yes & $2.64(1.37-5.07)^{b}$ & $2.09(0.95-4.61)^{\mathrm{a}}$ \\
\hline \multicolumn{3}{|l|}{ Hypertension } \\
\hline No/Yes & $1.53(0.89-2.74)$ & $1.38(0.61-2.99)$ \\
\hline \multicolumn{3}{|l|}{ Smoking } \\
\hline No/Yes & $1.57(0.92-4.17)$ & $1.41(0.71-3.03)$ \\
\hline \multicolumn{3}{|l|}{ Serum uric acid } \\
\hline Quartile 1 (2.6-4.7, mg/dL) & 1.00 & 1.00 \\
\hline Quartile 2 (4.8-5.6, mg/dL) & $1.25(0.59-2.65)$ & $0.56(0.88-1.72)$ \\
\hline Quartile $3(5.7-6.3, \mathrm{mg} / \mathrm{dL})$ & $1.62(1.22-5.60)$ & $1.16(0.37-3.57)$ \\
\hline Quartile 4 (6.4-9.2, mg/dL) & $2.42(1.12-5.20)^{a}$ & 2. $21(1.14-4.94)^{a}$ \\
\hline \multicolumn{3}{|l|}{ High Sensitive CRP } \\
\hline Quartile 1 (0.1-0.9 mg/dL) & 1.00 & 1.00 \\
\hline Quartile $2(1.0-2.9 \mathrm{mg} / \mathrm{dL}$ & $2.06(1.04-5.81)^{\mathrm{a}}$ & $1.94(1.03-3.66)^{a}$ \\
\hline Quartile 3 ( $\geq 3.0 \mathrm{mg} / \mathrm{dL}$ ) & $2.44(1.45-3.16)^{b}$ & $2.57(1.55-4.69)^{\mathrm{b}}$ \\
\hline
\end{tabular}

Adjusted for age, gender, diabetes, hypertension, and smoking. CAD, coronary artery disease; $\mathrm{OR}$, odds ratio; $\mathrm{Cl}$, confidence interval. $\boldsymbol{p}<0.05 ; \boldsymbol{p}<0.01$.

role played by inflammation in coronary artery disease. There is a consistent relationship between the baseline Hs-CRP levels and the risk for future cardiovascular incidents in all populations (Torzewski et al., 2000; Cao et al., 2003; Ockene et al., 2001). Although the underlying inflammatory mechanisms in coronary artery disease are well known, the role of inflammation in the pathogenesis of isolated coronary artery ectasia (CAE) are yet to be cleared. The post-mortem histopathological results obtained from the histopathological studies conducted for this purpose have demonstrated that the vascular inflammation in patients with CAE is more large-scale and severe than in coronary artery disease. This condition probably involves all the vascular layers along the coronary circulation and plays a role in the pathogenesis of CAE. In our study, similar to the coronary artery disease, the Hs-CRP levels in patients with coronary artery ectasia were higher in comparison to individuals with normal coronary arteries.

The relationship between serum uric acid level and cardiovascular diseases has been known for nearly half a century or more. Many studies have shown the relationship between hyperurecemia and coronary heart disease, cardiovascular disease, and death (Nagahama et al., 2004; Leyva et al., 1997). In a study by Sen and coworkers (2009) the blood uric acid levels in patients with CAE were observed to be high and this was associated with the effect of uric acid increasing the oxidative stress on the endothelium. Studies attributing endothelium dysfunction to UA have not revealed a clear mechanism with respect to pathogenesis. It has been shown in laboratory and clinic research that UA level plays a role in platelet adhesion, the formation of free radicals, and in oxidative stress (Emmerson 1979; Vasquez-Vivar et al., 1996; Anker et al., 1997; Alberti \& Zimmet, 1998; Reaven, 1994). Recent experimental and clinical studies have shown that elevated UA levels correlate with systemic inflammation, increased CRP levels, endothelial dysfunction (Vasquez-Vivar et al., 1996; Anker et al., 1997; Alberti \& Zimmet, 1998; Reaven, 1994; Kato et al., 1995). Uric asid alters the proliferation migration and NO release of human vascular cells, mediated by the expression of CRP, calls for careful reconsideration of the role of UA in cardiovascular disease. In our study, as is the case in coronary artery disease, the uric acid levels in the patients with coronary artery ectasia were observed to be higher in comparison to the individuals with normal coronary arteries.

The severity of ectasia was evaluated and categorized according to Markis (Markis et al., 1976). In line with the Markis classification, patients with isolated CAE in our study were divided into four subgroups based on the extent of the ectasia. In the study by Sen and coworkers (2009) no significant relationship was observed between the extent of the coronary artery ectasia and the uric acid levels. However, when individuals with type I coronary artery ectasia were compared with those with Type IV coronary artery ectasia, the blood uric acid and Hs-CRP levels were observed to be higher in Type I. This may point out that the increase in the uric acid and HsCRP levels are associated both with the atherosclerotic process and the severity of the ectasia. In our study also, when patients were evaluated according to the uric acid and Hs-CRP levels, it was observed that the increase in both the uric acid and Hs-CRP levels were closely associated with coronary artery ectasia. The multiple regression analysis has revealed independent relationships between uric acid and Hs-CRP, and diabetes mellitus and coronary artery ectasia. Previous studies have expressed different views on the relationship between coronary artery ectasia and diabetes. However, our study has pointed to an independent relationship between diabetes and the development of coronary artery ectasia.

\section{CONCLUSION}

Finally, our study has demonstrated that the blood uric acid and Hs-CRP levels are higher in individuals with coronary artery ectasia and that there is a relationship between these parameters and the extent of the ectasia. Also, these parameters were demonstrated to be independently associated with coronary artery ectasia.

\section{LIMITATIONS}

In our study, the uric acid and Hs-CRP levels in individuals diagnosed with coronary artery ectasia based on coronary angiography were assessed. There is a need for prospective studies where the development of coronary artery ectasia in individuals with high blood uric acid and Hs-CRP levels is evaluated. Also, cellular studies where the mechanisms leading to coronary artery ectasia in individuals with high blood uric acid and Hs-CRP levels are needed. 


\section{REFERENCES}

Alberti KG, Zimmet PZ (1998) Definition, diagnosis and classification of diabetes mellitus and its complications. Part 1: diagnosis and classification of diabetes mellitus provisional report of a WHO consultation. Diabet Med 15: 539-553.

Anker SD, Leyva F, Poole-Wilson PA, Kox WJ, Stevenson JC, Coats AJ (1997) Relation between serum uric acid and lower limb blood flow in patients with chronic heart failure. Heart 78: 39-43.

Befeler B, Aranda MJ, Embi A, Mullin FL, El-Sherif N, Lazzara R (1977) Coronary artery aneurysms: study of the etiology, clinical course and effect on left ventricular function and prognosis. Am J Med 62: 597-607.

Cao JJ, Thach C, Manolio TA, Psaty BM, Kuller LH, Chaves PH, Polak JF, Sutton-Tyrrell K, Herrington DM, Price TR, Cushman M (2003) C-reactive protein, carotid intima-media thickness, and incidence of ischemic stroke in the elderly: the Cardiovascular Health Study. Circulation 108: 166-170.

Emmerson BT (1979) Atherosclerosis and urate metabolism. Aust N Z J Med 9: 451-454.

Falsetti HL, Carrol RJ (1976) Coronary artery aneurysm. A review of the literature with a report of 11 new cases. Chest 69: 630-636

Fang J, Alderman MH (2000) Serum uric acid and cardiovascular mortality the NHANES I epidemiologic follow-up study, 1971-1992: National Health and Nutrition Examination Survey. J Am Med Ass 283: $2404-2410$

Glagov S, Weisenberg E, Zarins CK, Stankunavicius R, Kolettis (1987) GJ. Compensatory enlargement of human atherosclerotic coronary arteries. N Engl J Med 316: 1371-1375.

Hartnell GG, Parnell BM, Pridie RB (1985) Coronary artery ectasia: its prevalence and clinical significance in 4993 patients. Br Heart J 54: 392-395.

Kato M, Hisatome I, Tomikura Y, Kotani K, Kinugawa T, Ogino K, Ishida K, Igawa O, Shigemasa C, Somers VK (2005) Status of endothelial dependent vasodilation in patients with hyperuricemia. Am J Cardiol 96: 1576-1578.

Kosar F, Sincer I, Aksoy Y, Topal E, Cehreli S (2005) Increased aortic stiffness in patients with coronary artery ectasia. Coron Artery Dis 16: 499-504.

Leyva F, Anker S, Swan JW, Godsland IF, Wingrove CS, Chua TP, Stevenson JC, Coats AJ (1997) Serum uric acid as an index of impaired oxidative metabolism in chronic heart failure. Eur Heart $J$ 8: 858-865

M. Koga, J. Murai, H. Saito, M. Mukai, S. Kasayama (2009) Serumglycatedalbumin, but not glycatedhaemoglobin, is low in relationtoglycemia in hyperuricemic men. Acta Diabetol 47: 173-177
Markis JE, Joffe CD, Cohn PF, Feen DJ, Herman MV, Gorlin R (1976) Clinical significance of coronary artery ectasia. Am J Cardiol 37: $217-222$

Nagahama K, Iseki K, Inoue T, Touma T, Ikemiya Y, Takishita S (2004) Hyperuricemia and cardiovascular risk factor clustering in a screened cohort in Okinawa. Japan Hypertens Res 27: 227-233.

Ockene IS, Matthews CE, Rifai N, Ridker PM, Reed G, Stanek E (2001) Variability and classification accuracy of serial high-sensitivity C-reactive protein measurements in healthy adults. Clin Chem 47: 444-450.

Puig JG, Michán AD, Jiménez ML, Pérez de Ayala C, Mateos FA, Capitán CF, de Miguel E, Gijón JB (1991) Female gout: clinical spectrum and uric acid metabolism. Arch Intern Med 151: 726-732.

Puig JG, Ruilope LM (1999) Uric acid as a cardiovascular risk factor in arterial hypertension. J Hypertens 17: 869-872.

Reaven GM (1994) Syndrome X: 6 years later. I Intern Med Suppl 736: 13-22.

Seabra Gomes R, Somerville J, Ross DN, Emanuel R, Parker DJ, Wong M (1974) Congenital coronary artery aneurysms. Br Heart J 36: 329-35.

Sen N, Ozcan F, Uygur B, Aksu T, Akpinar I, Cay S, Cetin M, Sökmen E, Akçakoyun M, Maden O, Balbay Y, Erbay AR (2009) Elevated serum uric acid levels in patients with isolated coronary artery ectasia. Turk Kardiyol Dern Ars 37: 467-472.

Stefanadis C1, Dernellis J, Tsiamis E, Stratos C, Diamantopoulos L, Michaelides A, Toutouzas P (2000) Aortic stiffness as a risk factor for recurrent acute coronary events in patients with ischemic heart disease. Eur Heart J 21: 390-396.

Swaye PS, Fisher LD, Litwin P, Vignola PA, Judkins MP, Kemp HG, Mudd JG, Gosselin AJ (1983) Aneurysmal coronary artery disease. Circulation 67: 134-138.

Torzewski J1, Torzewski M, Bowyer DE, Fröhlich M, Koenig W, Waltenberger J, Fitzsimmons C, Hombach V (1998) C-reactive protein frequently co-localizes with the terminal complement complex in the intima of early atherosclerotic lesions of human coronary arteries. Arterioscler Thromb Vasc Biol 18: 1386-1392.

Torzewski M, Rist C, Mortensen RF, Zwaka TP, Bienek M, Waltenberger J (2000) C-reactive protein in the arterial intima: role of $\mathrm{C}$-reactive protein receptor-dependent monocyte recruitment in atherogenesis. Arterioscler Thromb Vasc Biol 20: 2094-209.

Vasquez-Vivar J, Santos AM, Junqueira VB, Augusto O (1996) Peroxynitrite-mediated formation of free radicals in human plasma: EPR detection of ascorbyl, albumin-thiyl and uric acidderived free radicals. Biochem J 314: 869-876. 